\title{
أثر نظرية التلقي في النقا العربي الحديث
}

م.د.حسنة محمد رحمة خريجة كلية التربية للبنات

تدريسية في ثانوية هالة بنت خويلد الأدبيةـ الكرخ الثانية

07712210849

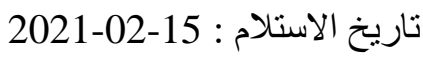

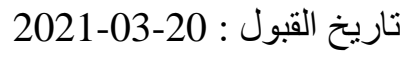

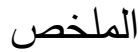

أروم في هذا البحث دراسة نظرية التلقي من حيث تأثيرها على النقد العربي الحديث ؛ وبسبب كثرة

الدراسات التي أقيمت حول هذه النظرية لا نستطيع الإحاطة بتعريفها في بضع كلمات ، ولكن يكفي أن نشير إلى أنّها من النظريات الحديثة التي ظهرت عند الغرب والألمان خاصة ـ وأثرت بشكل جلي في النقد الغربي ولها يدها أيضاً على النقد العربي، وهذا ما تثير إليه كثرة الدراسات التي أقيمت في هذا الميدان ؛ وذلك لأهمية نظرية التلقي إذ إنّا تستند إلى تحول عام من الإهتمام بالمؤلف إلى الإهتمام بالنص والقارئ وسيتم التركيز في هذا البحث على أعمال الناقدين إيزر وياوس ؛ لإنّهما قطبان مهمان في نظرية التلقي، فضلاً عن ذلك لقيمة أعمالهما من جانب ، ومن جانب آخر ؛ لأنّ إسلوبهما في معالجة هذه النظرية يعتمد على القاريء ، كما أنّ مشروع إيزر النقدي يكمل مشروع ياوس النقدي فهما يهتمان بالنص والقارئ على الرغم من الاختلافات الموجودة بين إيزر وياوس إلّا إنّ مشروعهما النقدي أحدهما يكمل الآخر. الكلمات المفتاحية: نظرية التلقي ، الأثر، النقد الحديث ، ياوس ، إيزر . 
The impact of the receptive theory in modern Arab criticism

Assist. Dr. HASSNA MOHAMMED RAHMA

Graduate of the College of Education for Girls

Academic title / teacher Specialization of Doctorate Degree in Philosophy of Arabic LanguageArabic Language Teacher in Literary Secondary school of HALA BINT KHOWAYLED ( AI- Karkh 2)

Receipt date: 2021-02-15

Date of acceptance: 2021-03-20

\begin{abstract}
I want in this research to study the theory of receptivity in terms of its impact on modern Arab criticism. Because of the large number of studies that have been conducted on this theory, we cannot get its definition in a few words, but it suffices to point out that it is one of the modern theories that appeared in the West and the Germans in particular. She clearly influenced Western criticism and also has a hand on Arab criticism, and this is what is indicated by the large number of studies conducted in this field. This is due to the importance of the receptivity theory, as it is based on a general shift from an interest in the author to an interest in the text and the reader. This research will focus on the work of critics Iser and Yeos. Because they are two important poles in the theory of receptivity, in addition to the value of their actions on the one hand, and on the other hand; Because their approach to this theory depends on the reader, and Iser's critical project complements the Yaws critical project, as they care about the text and the reader despite the differences that exist between Iser and Yaws, but their critical project is one of them complements the other.
\end{abstract}

Kye words: Receipt Theory, Impact, Modern Criticism, Yaus, Eiser. 
تعد نظرية التلقي واحدة من أهم المناهج النقدية الحديثة في دراسة الأدب ونقده، ومن الضروري أن نثير هنا إلى أنّ التلقي

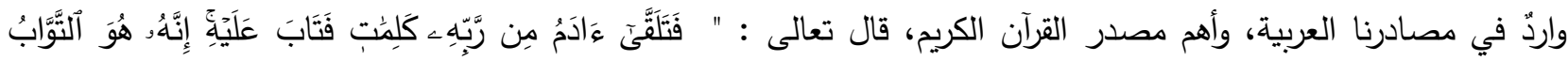

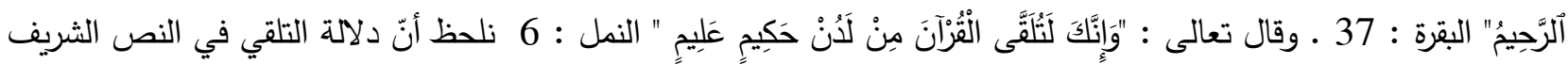
تثير إلى نيل المواطن الصعبة التي تحتاج إلى رياضة النفس والعقل وهذا المعنى أشدّ تطابقاً لما نرمي إليه، إذ إنّ الإبداع النقدي يتطلب مشاركة العقل والقلب لإنتاج النص وشق شفراته، وقد استطاعت نظرية التلقي - على الرغم - من حداثتها أن تقرض نفسها في تاريخ الفكر الأدبي وتحتل مكانة متميزة بين المناهج النقدية، لقد جاءت هذه النظرية لتؤسس بعداً جمالياً للنص يتمثل في قراءة النص الأدبي من خلال إضافة عناصر جديدة لككونات العملية الإبداعية، والكثف عن أمور جوهرية عند تحليل وتأويل النص من خلال تركيزها على محور أساسي ألا وهو القاريء.

إنّ دراستي لهذا البحث تهتم ببيان العلاقة بين النقد العببي الحديث ونظرية التلقي فمن خلال الكلمة الأولى من البحث هي أ ثر بوصفها كلمة أولى في عنوان هذا البحث ، وهذا يعني : إنّ هنالك جسوراً للتواصل والاتصال بين النقد العبي الحديث

$$
\text { ونظرية التلقي التي ظهرت عند الغرب . }
$$

إنَّ قولنا الأثر يبين أنّ الطرف المستقبل(العرب) كان مهيئًا للأخذ والتأثر في النظرية الوافدة من الغرب ـ كما أنّ ذكر الأثر يثير إلى قوة هذه النظرية ومرونتها حيث إنها لو لم تمتلك عناصر قوية ومتماسكة ما كان لها أن تغري بالأخذ منها والتأثر بها. ولهذه النظرية أعلامها ،وأهم علمائها هانس روبرت ياوس Hans Robert Yauss وفولفكانك إيزر Wolfgng Iser وينتمي هذان العلمين إلى مدرسة كونسانس التي أعادت بناء تصور جديد لففهوم العملية الإبداعية ، من حيث تكونها عبر الزمن التاريخ وطرق اشتغال القراءة ودور القارئ في انتاج هذه العملية أو النص الأدبي •

وقد أفادت من هذه النظرية الكثير من الدراسات ، منها على سبيل المثال لا الحصر،دراسة التلقي والتأويل مقاربة نسقية، للاكتور محد مفتاح، ودراسة نظرية الإستقبال، مقدمة نقدية، لروبرت هولب، ترجمة دكتور عز الدين إسماعيل وترجمها أيضاً، 
الأستاذ رعدعبدالجليل، ودراسة نظرية التلقي بالأدب الحديث، للدكتور يوسف نورعوض، ودراسة فعل القراءة نظرية جمالية التجاوب، فولفكانك إيزر، ترجمة دكتور حميد الحمداني، ودكتور الجلالي ، هذه الدراسات المذكورة أعلاه هي فيض من غيض فقد أقيمت دراسات كثيرة في هذا الميدان •

وفي عنوان هذا البحث نقرأ( النقد العربي الحديث ) كلنا يعلم أنّه لا يمكننا بتاتاً الوقوف عند كل النقد العربي الحديث من حيث الأثر الذي تركته هذه النظرية فيه ولكننا سنقف عندما يمت إلى هذا البحث بصلة وخاصة النقد العربي الحديث وأثر نظرية التلقي فيه وذلك للتفاعل الذي بدأ بينه وبين هذه النظرية . · نظرية التلقي والنقدالحديث

إنّ حديثا عن أثر هذه النظرية في النقد العربي الحديث لا يعني إنّا سنحيط بجميع تجليات هذا الأثر؛ وذلك لأمرين اثثين: أولهما ، إنّ هذا الصنيع في حاجة إلى جهود متضافرة وفي ميادين عدة وثانيهما ، إنّ هذه النظرية ولّدت دراسات كثيرة عند الغرب والعرب ، وهذا ما يجعل أثرها مستمراً وفي حاجة إلى متابعة ، مما يجعل الحديث عن أثر هذه النظرية في نقدنا الحديث ليس نهائياً إذ إنّ أثرها رهين بالتطور التاريخي وما يمكن أن يحمله معه في هذا المجال من دراسات متجددة ومتطورة بمرور

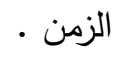

والثيء الإيجابي الأول الذي نود الإثارة إليه هو إنّ النقد العربي الحديث وطأ تخوم نظرية التلقي بجدارة كما سنرى ذلك وهذا الأمر له هميته في دراسات نقدية عدة ويظهر هذا من خلال الإقبال على هذه النظرية محاولة فلك رموزها من لدن بعض الباحثين والنقاد العرب • وهذه الخطوة تجعلنا نطل على ما تدخره هذه النظرية من عناصر إيجابية. نظرية التلقي عند الغرب

أبانت نظرية التلقي عند الغرب عن بعد نقدي استطاعت من خلاله أن تناقش عدة قضايا مهمة في مجال النقد الادبي • ومن أهم ما جاءت به هذه النظرية إنّها أرادت أن تُخرج الغرب مما كان يعانيه من مأزق منهجي ، واضطراب في الدراسات الادبية حيث كان التوجه إلى نظرية التلقي بوصفها حلاً ممكناّ لأزمة المنهجية الأدبية نعني هنا إنّ المنظر (ياوس) يهتم بالتلقي في حين إنّ المنظر (إيزر) يهتم بالإستجابة والتأثير • (هولب، 1994 : 32_38) . 
إنّ هذه الإزمة المنهجية أثار إليها إيزر في كتابه (من قضايا التلقي والتأويل) لإيزر، ترجمه أحمد بو حسن. ولا تخفى علاقة

النقد العربي الحديث بالنقد الغربي قبل أن تستوي هذه النظرية على سوقها إذ إنّه كان يتأثر بالمناهج الغربية من نفسية ، واجتماعية ، وشكلانية وغيرها ـ وهو كذلك ظل عرضة سابقاً يعاني من قصور هذه المناهج كما عانى الغرب، ومن ثم فهو في مسيس الحاجة إلى من يقوم بعمل نقدي تجاه هذه المناهج ، فيرشده إلى بعض مواطن القوة أو الضعف فيها لم يكن قد انتبه إليها من قبل، أو انتبه إليها فيما بعد وأخذ يبحث هو الآخر عن حلول أخرى.

نظرية التلقي والمناهج السابقة

إنّ السؤال الذي يطرح نفسه هنا هو هل استطاعت نظرية التلقي أن تكثف عن مواطن الضعف في المناهج السابقة وكيف ذلك ؟ وهل يفيدنا ذلك الأمر أم لا ؟

لقد خلخلت نظرية التلقي بعض المنطلقات التي سادت في النقد الغربي وذلك برد الإعتبار الكافي إلى القارئ الذي أضحى عندها من العناصر المهمة في العمل الإبداعي • وهذا التوجه يخالف التركيز على المؤلف أو النص الذي كان سائداً آنذاك (هولب، 1994 : 29) في المناهج السابقة دون إعطاء الأهمية الكاملة للقارئ . ويعد هذا الدور الذي قامت به نظرية التلقي نابعاً من التطورات الفكرية والاجتماعية والثقافية والسياسية التي عرفها المجتمع الغربي والمانيا الغربية آنذاك (هولب، 1994 : 56) وهذه الثورة كانت تعبر عن واقع معاش متتاقض يطمح إلى التغيير والإنقلاب على الوضع السائد . وسننظر الآن إلى موقف هذه النظرية من الموروث النقدي الغربي أو ما كان يعيش إلى جانبها من المناهج • 1 المنهج الشكلاني

في حديثنا عن المنهج الثكلاني ينبغي أن نعرف "إنّ العمر المنهي الحديث ينطوي على ثلاث لحظات : لحظة المؤلف، وتمثلت في نقد القرن التاسع عشر التاريخي، والنفسي، والإجتماعي... ثم لحظة النص التي جسدها النقد البنائي في الستينات من هذا القرن، وأخيراً لحظة القاريء أو المتلقي كما في اتجاهات ما بعد البنيوية، ولا سيما نظرية التلقي في السبعينات منه " ( صالح ، 2001 : 32). تعد الثكلانية في طليعة الإتجاهات التي رفضت تقيد الفن بالواقع، حيث إنها عنيت بالثكل الفني في محاولة منها للتخلص من أسر مضامين المجتمع. (مبروك، 2002 : 12). 
لقد كان للمنهج الثكلي دوره في الحياة النقدية عند الغرب . وقد عرف هذا المنهج تطوراً مهماً على يد صانعيه ، ولسنا هنا بصدد الوقوف عند مكونات هذا المنهج ، وذكر الأسس التي قام عليها وإنّما سنكتفي بالإثارة إلى ما له صلة بموضوعنا . وعلاقة هذا المنهج بنظرية التلقي .

لقد أسهح الثكلانيون الروس بتوسيعهم مفهوم الثكل بحيث يندرج فيه الإدراك الجمالي ، وبتعريفهم للعمل الفني : بإنّه مجموعة عناصره الثكلية فقط وبجذهم النظر إلى عملية التفسير ذاتها - إذ أسهم النقاد فيما بعد في خلق طريقة جديدة للتفير ترتبط ارتباطاً وثيقا بنظرية التلقي، إذ إنّ نظرية التلقي عدت البنيوية وما بعد البنيوية مميتة للمؤلف، إنّها أماتت المؤلف (عوض، 1994 : 44) وبالنظر إلى أعمال الثكلانيين نلحظ أنّ نظرية التلقي تبنت مجموعة من المصطلحات ترجع في أصلها إلى هؤلاء البنيويين نقرأ في نقدهم مثلاً، ( أفق التوقعات ) عند ( ياوس ) وفكرة ( الفجوات ) أو ( المبهمات ) عند ( ايزر ) نلحظ أنّ هذين المصطلحين لهما صلة وثيقة بمفهوم (( السائد )) أو ما يسمى أيضاً ب (( المهيمنة )) Dominante التي اعتمدها الشكلانيون؛! هولب، 1994 : 52).

لقد خصص روبرت هولب حيزاً من كتابه ( نظرية التلقي مقدمة نقدية ) للحديث عن الثكلانية الروسية وأظهر من خلال ذلك أوجه الالتقاء بين ( ميكاروفسكي ) الذي يندرج ضمن امتدادات الثكلانيين وبين نظرية التلقي، وطالما أشارت إلى ذلك أيضاً في دراستها La Reception Litteraire Ibseh الثكلانيين ونظرية التلقي ، فإنّ المنظرين ورواد هذه النظرية لم يقفوا من أعمال الشكلانيين موقف المسلم بكل ما جاءوا به . وإنّما هناك بعد نقدي نلمسه في ما قام به ( ياوس ) و ( إيزر ) • فإذا كانت الثكلانية تتوجه نحو ( الفن للفن ) فإن ذلك عند ( ياوس ) من أوجه النقص ، يقول هولب :( ووجه النقص في المنهج الثكلاني في نظر ياوس يتعلق قبل كل شيء ، بالميل إلى جماليات الفن للفن ). (هولب ، 1994 : 83) •

وهنا تظهر المفارقة الموجودة بين الثكلانيين ونظرية التلقي حيث إنّ المنهج الثكلي كما هو عند أعلامه يسير نحو إظهار أدبية الادب ـ بينما نجد إنّ نظرية التلقي تركز أساساً على القاريء • وتدافع عن حضوره في العمل الإبداعي وهذا لا يعني إنّ نظرية التلقي لا تلغي النص وتهمشه ، بل إنها تنظر إليه من خلال علاقته بالقاريء ، ومن خلال التقاعل الحاصل بينهما ، 
يقول (إيزر ) في هذا الثأن : (( وإذا كان الموقع الحقيقي للعمل يقع بين النص والقاريء فمن الواضح إنّ تحقيقه هو نتيجة التفاعل بين الإثنين)) • (برادة،1992: العدد، 6ص 19).

$$
\text { 2 2 }
$$

إنً "رواد نظرية التلقي يلقون على الماركسية تبعة الأزمة التي حدثت في الأدب ، وفي انحراف القاريء فكرياً في تعامله مع النص ونقاد المانيا الثرقية يصفون نظرية التلقي بأنها محاولة برجوازية تدل على إفلاس روادها في إيجاد البدائل للمعالجة الماركسية". (عبد الواحد ، 1996 :16) إذ إنّ تأكيد الماركسية على دور المجتمع في نشوء النص الأدبي جعلها تلغي دور القاريء، فلقارئ خصوصية فردية وذاتية تختلف عن مجتمعه في بعض المواقف والآراء. ( قديد ، ذياب 2004 : 187). على العكس من نظرية التلقي فهي تؤكد على حرية القاريء في الكثف عن معنى النص فمعاني النص تتعدد بتعدد القراء " فهي لا تحلم بزعزعة أفق أو تجاوز معيار القاريء، بل ترضى من خلال ملامستها للكائن أن تكرر ذواتاً سابقة عليها". ( مونسي ، $\cdot(279: 2000$

إنّ نظرية التلقي وجهت نقداً للماركسية في بعض مفاهيمها نقرأ عند ( ياوس ) نقداً في مقالته ( الإستثارة ) انتقاداً لمفهوم ( الإنعكاس ) إذ إنتقد كلاً من ( لوكاش ) و ( كولدمان ) · (هولب، 1994 :151) إذ إنّ الماركسية تتظر إلى الأدب بأنّه يعكس القضايا في المجتمع الذي تتحدث عنه فتجعل الأدب مرآة للواقع والمجمع، فالأدب تجربة إنسانية هدفها مشاركة الأديب بهذه التجربة بحيث يؤثر في المتلقي وشعوره لكي يسهم في تغيير واقعه الإجتماعي. (الماضي، 2005 : 73_77) . ونجد إنّ النقد العربي الحديث في حاجة إلى زعزعة مجموعة من الأفكار التي ترسخت لديه أثناء معاملته مع مجموعة من المناهج النقدية التي سادت لاى الغرب ، تلك المناهج التي كانت تركز اهتمامها أمّا على المؤلف أو المؤلَّف وبذلك تكون حاجتنا إلى هذه النظرية ماسة لتطوير مسير النقد العربي • وقد أحس بذلك مجموعة من النقاد المترجمين للنصوص المتعلقة بهذه النظرية . يقول د. حميد الحمداني و د. الجلالي الكدية في تقديمها لترجمة فصول من كتاب ( فعل القراءة نظرية جمالية التجاوب في الادب ). (( ولا شك إنّ الحاجة الأساسية لمثل هذه النظريات الجديدة في العالم العربي شديدة الإحاح ؛ لأنّ تاريخ النقد العربي 
أيضاً تركزت فيه كثيراً سلطة المؤلف إلى الحد الذي جعل النقاد يعدون النصوص كمستودعات للمعاني ، وإنّ القراءة ليست شيئًا

آخر سوى فعل إفراغ هذه المستودعات من محتواها وإعلانها للآخرين )) • (إيزر ، ترجمة الكدية، الحمداني، 1992: 7) .

$$
\text { ياوس ونظرية التلقي }
$$

إنّ المحرك الأول لياوس هو تقديم نظرية تعنى بدراسة تاريخ الأدب ، وعلى هذا الأساس كان يريد أن يسد الفجوة الموجودة بين الثكلانية والاتجاه الماركسي ويجمع بين الجوانب الإيجابية في كلا الإتجاهين . وهو بذلك يهدف (( إلى تلبية المطلب الماركسي في الوسائط التاريخية عن طريق وضع الأدب في السياق الأوسع للأحداث كما أنّه احتفظ بالمنجزات الثكلانية عن طريق إحلاله الذات المدركة في المركز من اهتماماته وعلى هذا النحو اتحد التاريخ وعلم الجمال (هولب، 1994 : 150) . إنّ وقوف (( ياوس )) عند نقطة التاريخ الأدبي يعد نقطة إيجابية وملمحاً من الملامح التي يمكن الإستفادة منها ؛ لأنّ التاريخ الأدبي العربي أيضاً كثيراً ما عانى ويعاني من الإهمال والتجاوز في حين نجد إنّ الناقد ياوس قد أعاد إلى التاريخ الادبي قوته وديناميته (هولب،1994 : 150) . نرى أنّ ياوس كان يتوسم تاريخاً أدبياً (( يؤدي دوراً واعياً يصل الماضي بالحاضر وسوف يطلب من مؤرخ التلقي الادبي ، بدلاً من مجرد أن يتقبل الموروث بوصفه معطى أن يعيد التفكير على الدوام في الأعمال المعترف بها مبدئياً في ضوء كيفية تأثرها بالظروف والأحداث الجارية وتأثيرها فيها )). (إيزر ، ترجمة، الحمداني،الكدية، 1995 : 6_7) • أثرياوس في النقد العربي الحديث وما دمنا هنا بصدد تأثير ياوس وإيزر في النقد الأدبي لا بأس بأن نشير إلى مصطلح ( افق التوقع) نشير إلى إنّ ياوس، قال : (( نعني بأفق الإنتظار نظام الحالات القابلة للتحديد الموضوعي... إنّ العلاقة بين العمل الأدبي الجديد وأفق توقع الجمهور • أن تكون موسومة بالتطابق (عندما يتعلق الأمر بعمل عادي) أو تتنهي بتغيير هذا الأفق (في حالة انزياح العمل)... تخييب أفق التوقع... إنّ قيمة العمل الأدبي الجمالية الفنية تتجلى في مدى خلخلته... للمعايير الفنية التي تتحكم في أفق توقع

$$
\text { الجمهور عبر قراءاته المتعددة...). (ياوس، } 2016 \text { : 55). }
$$


نذكر في هذا المجال دراسة الدكتوربوحسن استغل هذا المصطلح أيضاً من خلال استعماله ( أفق الانظار ) للقيام بتعقيب للنقد العربي الحديث ، وقال : (( سأقدم هنا خططاً أولية لقراءة نقدنا العربي الحديث بالإستعانة بمفهوم ( أفق الانتظار ) كما جاء عند ( ياوس ) وقد حصر الباحث هذا التعقيب في ثلاثة مراحل (مفتاح، 1993 :82). _ بداية القرن العشرين وكان فيه لانتظارات المؤلف : الثاعر او الناثر دور كبير في توجيه القراءة وخلق قاريء نموذجي يستجيب مع استراتيجية المؤلف ويحصل بذلك توافق انتظار المؤلف مع أفق انتظار القاريء .. _ 2 مرحلة تعارض افق الانتظار : هذه المرحلة التي بدأ فيها أفق الانتظار المنسجم يتعرض لنوع من التشويش على قيمه وذوقه وتقاليده اللغوية والجمالية وغيرها ، وقد تولد هذا الانتظار مع مرحلة الصراع بين القديم والحديث بين التقليديين والمجددين منذ أن ظهرت كتابات العقاد وميخائيل نعيمة وطه حسين ... ـ 3 ـ مرحلة تباعد أفق الإنتظار : هذه المرحلة هي التي بدأ فيها أفق إنتظار القاريء يبتعد فيها عن أفق إنتظار المؤلف أو العكس بحكم عدم وجود حوار بين الافقين وعدم تصارع بينهما (مفتاح ، 1993 : 83) • وإلى جانب الإستفادة من مصطلحات هذه النظرية في المجال الشعري فإنّا نجد الإستفادة أيضاً في مجال السرديات العربية ، فهذا سعيد يقطين يقدم بحثاً في هذا المجال وهو تلقي العجائبي في السرد العربي الكلاسيكي : (( غزوة وادي السيسبان نموذجاً )). (مفتاح، 1993 : 38) ويعن الباحث دخوله في مجال التلقي ، بقوله : (( لنسم الجمهور الذي نتحدث عنه بـ ( المتلقي ) ومختلف ردود افعاله بـ ( التلقي ) ولنجعل من المتلقي والتلقي موضوعاً لبحثنا وتفكيرنا وأسئلتنا )). ( مفتاح، 1993 : 39) • إنّ نظرية التلقي من شأنها أن تتفع في مجال البحث في السرديات العربية وذلك من خلال الإهتمام بالإنتاج والتلقي على حد سواء وكذلك البحث في النشوء والتطور الذي يرجع بالأساس إلى ركيزة أساسية في نظرية التلقي وهي السعي نحو تاريخ أدبي فاعل . وهناك دراسات وابحاث تعتبر نظرية التلقي مرجعا لها أنجزت في مؤلف (( نظرية التلقي إثكالات وتطبيقات )) ومنها ما يتصل بالقصة القصيرة · (مفتاح ، 1993 : 88) أو ما يتعلق بالجانب بالبيداغوجي (مفتاح، (103 : 1993 وكلها تستفيد من الجهاز المفاهيمي لهذه النظرية ، وتسعى إلى الخروج من المأزق المنهي الذي كان يسبب تهميش المتلقي وإبعاده عن دائرة الضوه، ونذكر أيضاً مقالة الباحث الدكتور محمد العمري، إذ قال في حديثه عن : (( الرواية والاختيار : تأمل تاريخ الادب العربي من زاوية تلقي الثعر القديم )) فقبل أن 
يتحدث عن الرواية والاختيار في الادب العربي أظهر من خلال تقديمه لدراسته وعيه بأهمال تاريخ الادب العربي ورغبته في الاستفادة مما وصلت إليه نظرية التلقي في هذا المجال متمثلة في أعمال ياوس ويقول العمري في موضع آخر : ((نرى أنّ تاريخ الأدب اليوم متروي في المقررات الجامعية باعتبارها المعقل الأخير الذي يتحصن فيه التقليد والمحافظة فالكل يدرس تاريخ الأدب هناك وقلّ من يكلف نفسه عناء طرح الأسئلة التي صار تاريخ الأدب يطرحها لتجاوز حالة الركود التي يعانيها منذ عقود • إنّ مثل هذا الواقع ، هو الذي حدا بياوس منذ ثلاثة عقود إلى طرح أسئلة تاريخ الأدب بحدة منهاجية تقوم على استعراض المناهج الأدبية ومحاسبتها ثم الإنتهاء إلى اقتراح مدخل جديد لدراسة تاريخ الادب يعيد الاعتبار للملتقي)). ( هولب، 1994 : 152). أبان الباحث من خلال حديثه هذا عن مدى إفادته من بعض مفاهيم نظرية التلقي ومن ذلك ( الأفق ) و ( المتلقي ) هذا المتلقي الذي كان مختلفاً ومتتوعاً في القديم وكان لله أثره . وإذا نظرنا إلى التراث العربي القديم نجد إثارات مهمة إلى ( المقام ) وإذا كان القدماء يعرفون أهمية المقام ، فأولى بنا ونحن في عالم تطورت فيه المناهج أن نفطن إلى أهمية المقام سواء أكان في الإبداع القديم أم في الحديث، والحديث عن المقام هو حديث عن الاختلاف ولذلك تحدث د. العمري عن ثلاثة مقامات في دراسته : مقام الحياة الثعبية ، مقام الأدب الفصيح ، مقام الأدب الرسمي ، وكل مقام يتضمن ( أفقاً ) •

ولا بأس أن ننظر إلى مصطلح أفق كيف يشتغل عند قراءة الثعر العربي القديم كما هو الثأن هنا مع دراسة العمري الذي ، يقول : لقد حاول الشعراء الكبار دمج هذه الآفاق • ومن هنا جاء التقاوت الكبير في شعر أبي تمام . فقد كان من جهة يستجيب ( كما ذكر ) للمطلب الإبداعي المستتد إلى استيعاب وتمثل الجيد من الثعر العربي القديم • ويستجيب من جهة ثانية لموضوعات وأحوال مخاطبين لا تسمو همهم وثقافتهم إلى مستوى المعاناة الفنية (مفتاح 1993 : 71) ويتبين لنا من خلا هذه الدراسة رغم أنها في صفحات قليلة كيف يمكن لنا أن نستقيد من مصطلحات نظرية التلقي لأجل إضاءة بعض جوانب تاريخ

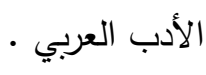
أثر إيزرفي النقد العربي الحديث وإلى جانب هذا العنصر الإيجابي الذي تحدثا عنه الناتج عن أثر استقبال نظرية التلقي في نقدنا الحديث نشير إلى عنصر إيجابي آخر وهو : جانب التأويل . 
إذ إنّ نظرية التلقي لكونها تعتمد على القاريء فإنّها تنظر إليه من زوايا عدة ـ ومن أهم الأمور التي تستأثر بالإهتمام في هذا

الصدد مسألة التأويل (الحمداني، 1995، 123) أي تأويل النصوص الإبداعية خاصة ولكن لماذا ترتبط نظرية التلقي بالتأويل ؟ إنّ هذه النظرية تتكيء على القاريء كما هو معروف ؛ ولأنّ علاقته مع النصوص تتحدد من خلال التأويل الذي يمارسه على النص كان لزاماً أن تركز هذه النظرية على هذا الجانب .

ويعد ( إيزر ) من النقدة الذين أعطوا أهمية للقارئ حيث إنّه جعل القراءة شرطاً ضرورياً للتأويل بقوله : (( هناك شيء واحد

واضح هو إنّ القراءة هي شرط مسبق ضروري لجميع عمليات التأويل الأدبي )). (ميلود حبيبي، د، ت : 167) •

ويتضح لنا من خلال هذا الإلتحام بين التلقي والتأويل إنّه لا يككن النظر إلى هذه النظرية بمعزل عن هذا العنصر الدينامي فيها ـ لكن لا تأويل بدون قراءة ـ فما الذي يسعى إليه التأويل في مجال قراءة النصوص ؟ إنّه يدخل في حوار مع النص . ويشمل عنصراً حيوياً فيه ـ وهناك تاريخ قائم لهذا التأويل ـ وما نريد تبيانه هنا إنّ هذا التأويل يختلف إذا قارنا بين تأويل القدماء للنصوص وتأويل نظرية التلقي ؛ لأنّ هذه النظرية لم تعد رهينة التأويل الأحادي الجانبي الذي يقف على المعنى الوحيد ويكثفي به ولذلك نجد إنّ (( ما أثار إهتمام إيزر منذ البداية هو السؤال عن كيفية أن يكون للنص معنى لدى القاريء وفي أي الظروف ـ وقد أراد - على النقيض من التقسير التقليدي الذي حاول أن يوضح المعنى الخبيئ في النص - أن يرى المعنى بوصفه نتيجة للتفاعل بين النص والقاريء أي بوصفه أثراً يمكن ممارسته وليس موضوعاً يمكن تحديده )) . إنّ هذا الدصطلح يشبه مصطلح الثرح، التفسير، وهنا يظهر لنا التحول الذي حدث من النظرة التقليدية للتأويل إلى النظرة التي تتحم في نظرية التلقي · حيث إنّ الدتلقي أصبح طرفاً معتمداً في انتاج المنى من خلال التأويل لكن هذا لا يعني عند إيزر إقصاء النص والتبثير بمركزية القاريء ، بل نراه يؤسس نظريته من خلال التفاعل الذي سيحصل بين النص وقارئه بفعل التأويل • وهذا ما يبينه ( إيزر ) ، بقوله : (( يمكن ان نستخلص إنّ للعمل الادبي قطبين نسميهما : القطب الفني والقطب الجمالي ، الأول: هو نص المؤلف، والثاني: هو التحقق الذي ينجزه القاريء ـ وفي ضوء هذا التقاطب يتضح إنّ العمل الأدبي ذاته لا يمكن أن يكون مطابقاً لا للنص ولا لتحققه بل لابد أن يكون واقعاً في مكان بينهما .... وإذا كان الموقع الفعلي للعمل يقع لِ لِ بين النص والقاريء فمن الواضح إنّ تحقيقه هو نتيجة للتفاعل بين الاثين)) • ( إيزر ، 1995 :12). 
ولعل قراءة تستمد روحها من نظرية التلقي من شأنها أن يكون لها نفع في طرح مجموعة أسئلة على النقد العربي القديم والحديث أيضاً . والسؤال الذي يمكن طرحه هنا هو هل كانت كل نصوصنا النقدية القديمة قابعة وراء القراءة الأحادية التأويل او هناك نصوص استطاعت أن تركب تعدد التأويل رغم زمنها المتقدم ؟ إنّ الإجابة عن هذا السؤال لا يمكن أن تكون إلّا من خلال القيام بدراسات متعددة في مجال قراءة التراث النقدي ويمكن أن تكون نظرية التلقي بمصطلحاتها مفيدة في هذا المجال ـ وإنّ مما يمكن اعتباره ايجابياً في اثر استقبال نظرية التلقي على النقد الحديث و المعاصر وعنصر التواصل الذي يحدث بين القارئ والنص اثناء عملية القراءة. والتواصل عامة ليس غريباً على هذه النظرية بل إنّ كلا من ( ياوس ) و ( ايزر ) ـ نقرأ اهتمامهما بهذا الموضوع في مناسبات عدة وبهذا يكون (( في وسع المرو أن ينتهي في يسر إلى إنّ نظرية التلقي لابد أن تبلغ مداها في نظرية عامة في الاتصال أو أن تصنف عن طريقها )). (بلمليح ، 1993 : 126) فهل استفاد الدرس النقدي العربي من هذا

من المعلوم إنّ بؤرة البحث في هذه النظرية توجد بالتفاعل الذي يكون بين النص وقارئه ؛ لأنّ هذا التفاعل كفيل بجعل القراءة فاعلة منتجة كما أنّه يضمن التواصل المطلوب بين الطرفين • ومن هنا نجد إنّ ( إيزر ) يفهم الاتصال الادبي على إنّه نشاط مشترك بين القاريء والنص يؤثر فيه احدها في الآخر في عملية تتظظم من تلقاء ذاتها ومن ثم فإنّ الفاعلية المستمرة للعمل الادبي ، تكمن في الخبرة بعملية القراءة وتثتق منها (هولب، 1994 : 250 _252) والتواصل هنا يقوم على المشاركة في خلق فاعلية مستمرة بين الطرفين وقد نظرت هذه النظرية إلى موضوع التواصل من خلال الشروط الواجب توفرها للقيام بالتواصل يقول إيزر (( إذا كان التواصل بين النص والقاريء ناجحاً ، فإنّه يجب على نشاط القاريء أن يكون مضبوطاً بوضوح بطريقة ما من

$$
\text { طرف النص )) (هولب، } 1994 \text { : } 250 \text { ) ( }
$$

معنى هذا إنّ القاريء من خلال علاقته في النص يكون النص موجهاً إليه بطريقة ما من خلال مجموعة من الصيغ والإثارات وما إلى ذلك مما يتضمنه النص المقروء . لكن هذا لا يعني إنّ النص يقهع نشاط القاريء ويوقفه ـ. بل هناك مجال يتحرك فيه القاريء أيضاً ـ ومن هنا يكون (( التواصل في الأدب هو عملية لا يحركها ولا ينظمها سنن معطى بل تفاعل مقنن وموسع بطريقة متبادلة بين ما هو صريح وضمني بين الكثف والاخفاء • إنّما هو خفي يحث القاريء على الفعل ولكن هذا الفعل لا يكون مراقباً أيضاً بما هو مكشوف )). ( هولب ، 1994 : 254 ) . 
إنّ نظرية التلقي هي جزء لا يتجزأ من نظرية الأدب، وسرعان ما خرجت من بين أحضان الأدب الألماني لتشق طريقها إلى آداب العالم الأخرى باحثة عن مكان لها أمّا نظريات الأدب الأخرى ، حيث إنّه وبعد سنوات من ظهورها وتطورها حطت رحالها بين أنواع الأدب العربي ، لكنها فثلت في الوصول إلى إجابات صحيحة ومقاربات سليمة لا تغفل أي عنصر من عناصر العملية التواصلية.

وبهذا فكما وصلت المناهج السياقية وكذلك من قبل ، فقد عرفت هذه النظرية كيف تصل هي الأخرى إلى الأخرى إلى ساحة الدرس الأدب العربي ، إذ تلقاها النقاد العرب كما تلقوا ما قبلها ، لكن تلقيهم هذا كان يشوبه نوع من الحذر اتجاه هذا الوافذ الجديد الذي انطلق من جانب طالما أهمل من قبل ألا وهو القارئ ، رغم وجود ملاحظة عامة حول طبيعة تلقي النقاد العرب للإتجاهات النقدية الوافدة إليهم من الغرب بصفة عامة ، إذ لوحظ إنّها " لا تتعدى تقديم جملة من الآراء النقدية التي تتنمي إلى إتجاهات نقدية عدة على الرغم من تبنيها لإتجاه محدد منها ، أو ربما التعامل مع آراء تتنتي إلى اتجاهات متعددة ومتباينة في منطلقاتها في دراسة واحدة ، وتقديمها كما لو أنّها منهجية واحدة منسجمة" (عبابنة ، 2004 : 400) . إنّ النظرة الجديدة في التعامل مع النص الأدبي من منطلق القاريء هي التي جعلت نظرية التلقي تحتل مكانة متميزة في الدراسات النقدية إذ خرجت من سلطة النص والمؤلف وأولت القاريء الإهتمام الأكبر حتى عدت الظاهرة الأدبية تستوي في علاقة النص بالقارئ • (عبد العظيم ، 1992 : 221). لذا فقد ( أصبح القاريء مفهوماً نظرياً أكثر منه واقعاً تجريبياً وفعلياً ، وما دام المؤلف قد مات فإنّ القاريء قد تمكن من مساحة النص) • ( الغذامي ، 1999 : 148) لذلك رأت نظرية التلقي أنّ الإدراك وليس الخلق ... والإستقبال وليس النتاج هو العنصر المنشئ للفن • ( سي هولب ، 1992 : 145) . إنّ القاريء في نظرية التلقي ينبغي أن يستتد إلى تجريته الجمالية لفك شفرات النصوص إذ إنّ القاريء حرٌ في إستقبال النص ، ويقدم لنا في الوقت نفسه سبباً فنياً ونفسياً لقبول هذه النظرية إجمالاً ، إذن القاريء يشارك في صنع النص فيتحول التركيز من موضوع النص إلى سلوك القراءة . ( عبد الواحد ،1996 : 21_22) • وإذ نؤوب إلى تراثنا النقدي العربي القديم نجد إنّ المبدع كان يهدف إلى التأثير في السامعين متوخياً سلامة الإسلوب ودقة المعنى ولا نعدم في تاريخنا النقدي العربي صوراً من مواقف التلقي التي تركز على علاقة النص بالقارئ ، فهذا الجاحظ يفهم أنّ 
المعول عليه في إستقبال النص هو استحسان السامع أو انصرافه عنه ، يقول : (... فإن رأيت الأسماع تصغي له والعيون تحدج إليه فانتحله... فإذا عاودت أمثال ذلك مراراً ، فوجدت الأسماع عنه منصرفة والقلوب لاهية ، فخذ في غير هذه الصناعة) • (الجاحظ ، 1975 : ( 193 ( )

من خلال هذا القول يتبين أنّ الإهتمام بالقراءة والقارئ ، ليس وليد النظريات الأدبية الحديثة فحسب ، بل لهذا الإهتمام إمتداد عبر التاريخ ففي الأدب العربي القديم إشارات عديدة ، إذ كانوا يهتمون كثيراً بالسامع ؛ لأن الأدب سابقاً كان شفاهياً . وفي الأدب الغربي في العصور الحديثة تجلى الإهتمام بالقاريء، ففي النقد الإنكليزي أشار إليه الروائي إدغار ألان بو إذ رأى أن المبدع قبل أن يباشر في الكتابة يضع في اعتباره نوع الأثر الذي ينوي إحداثه في قرائه ، ومثل هذا التأكيد على القاريء نجده عند الثاعر بودلير وكذلك عند بول فاليري ، إذ قال : "لأشعاري معنى الذي تحمل عليه"( محمد ، 1999 : 69). أما عن مكانة القاريء عند نقاد نظرية التلقي ، فقد جعلت للقارئ مكانة متميزة ، فهو عنصر فعال في التواصل الأدبي ، حيث يتعدى دوره كاتب النص نفسه ، إذ إنّ "تاريخ الأثر الفني يرتبط بالملتقى أكثر من ارتباطه بالمصدر ، وذلك ؛ لأنه يخضع لأنواع من التأويل التي تعتبر تحققات لتبادل التجربة الجمالية وإقامة الحوار الحيوي بين الأجيال ، بالرفض أوالقبول" (بلمليح ،

بل إنّ القاريء في نظرية التلقي هو المنتج الحقيقي للنص ، إذ (( لم يعدالنص الأدبي مجرد واحة يلقي القاريء بجسده على عثبها طلباً للراحة والإسترخاء ، بل يصبح هما يلازمه ويلاحقه... ولولم يعد القاريء مجرد مستهلك للنص ، بل أصبح منتجاً له ومشاركاً فيه بصورة أو بأخر )) • ( فوزي ، 1997 : 22) • إنَّ للدور الكبير الذي وضع للقارئ، فقد دعا أعلام نظرية التلقي إلى ضرورة إعادة النظر في نظريات الأدب السابقة لها إذ تحول الإهتمام من ثنائية (المؤلف /النص) إلى ثنائية (النص / القاريء) وتكون محاولة تجديدية في النقد الأدبي • 
إنّ نظرية التلقي لها إيجابيات وسلبيات، فمن الجوانب الإيجابية في النظرية إنّ النقاد والمهتمين بهذه النظرية تعاملوا مع تيارات فلسفية من خلال نظرية التلقي وهذا التعامل عمّق لديهم الرؤية لبعض التوجهات الفلسفية الغربية، فكانت هذه النظرية بمثابة الحافز للتدقيق في معرفة هذه التوجهات الفلسفية .

إنّ هذه النظرية إيجابية في مجال خلق اطار نظري مهم يعود على النقد والثقافة العربية عامة بشفرة نقدية جديدة تستتد إلى القاريء حيث إنّ الفكر النقدي العربي في جملته قديماً وحديثاً كثير آ ما انطوى على النص والمبدع دون الوقوف عند المتلقي أوالقارئ فنظرية التلقي تتنظم حول نثاط التلقي الأدبي أو الفني؛ لتصنع في النهاية إطاراً نظرياً خاصاً يكون بمثابة تطويراً أو إضافة إلى النظرية العا مة للنقد.

وإذا كانت هذه بعض الجوانب التي نراها إيجابية من جراء أثر نظرية التلقي في النقد العربي الحديث فأين تكمن الجوانب السلبية ؟ إذا أردنا أن نعرج إلى هذه الجوانب فإننا سنجد أولاً أنّ هذه النظرية ليست كاملة أو مكتملة لكي تستطيع أن تقدم العصا السحرية لفك رموز النصوص الإبداعية على اختلافها .

ومن جهة أخرى فانٍّ دراسة التلقي لا تستطيع الزعم بأنها المقاربة العلمية الوحيدة للأدب وللتواصل الادبي وهذا الأمر يجعل الباحث يتعامل مع هذه النظرية بحذر ومن هذا المنطلق إنّ نظرية التلقي تحمل في طياتها نقاط ضعف كما تحمل نقاط قوة . وهذا سيخرجنا من دائرة الانبهارفي نظرية التلقي والولوج إلى الحوار الجاد المبني على معرفة الغث من السمين. إنّ النقل الحرفي لهذه النظرية قد لا يكون عام الفائدة؛ لأنّه قد يلغي بعض الظواهر الثقافية الهامة في مجتمع من المجتمعات ، فقد تكون النظرية التي اقترحها (( ياوس )) والمنهاجية المحققة لها مفيدتين ، حقاً في دراسة بعض الآثار الأدبية وتأويل نوع المنتجات الشعرية في الادب العربي ... ولكن الامر ليس بهذه السهولة اذا ما أراد الباحث أن يتابع الآثار الأدبية التي ليست من القمم في شيء، أي قليلة الإبداع، فإن نظرية التلقي لاتهتم إلا بالنصوص الراقية؛ لأنها لا ترضى آفاق توقعات جمهورها، أما النصوص التي دون ذلك فهي ترضى توقعات جمهورها فهي لا تستحق الدراسة لذلك نرى إنّ عدم الاهتمام بالأنواع الأخرى من الآثار الأدبية - التي ليست من القمم ثغرة في نظرية جمالية التلقي. 
مجلة لارك للفلسدفة واللسداذيات و العلوم الاجتماعية المجلد (2) العدد (41) السذة (2021) بحوث الذغة الدربية أمّا عن مصطلحات نظرية التلقي، فهي ليست كلها غامضة وواضحة في الوقت نفسه؛ لذلك من الواجب علينا التعامل بوعي وحذر في الجانب المصطلحي من هذه النظرية ـ ومما تجدر الإشارة إليه في هذا الجانب إنّ ترجمة مصطلحات نظرية التلقي تختلف من ترجمة إلى أخرى.

أمّا عن مشكلة الترجمة فإنّ بعض الترجمات في هذا المجال تكتفي بترجمة فصول من كتاب مما يجعلنا نجهل وضعية الفصل المترجم داخل الكتاب ووضعية الفصول الأخرى من الكتاب المترجم إذ إنّا بحاجة إليها لتكتمل الصورة عن الكتاب المترجم •

وهذا يخلق صعوبات في التواصل الكافي مع الآخر ومع نظرية التلقي خاصة رغم أهمية ترجمة هذه النصوص في حد ذاتها . ولا يخفى كما ذكرنا آنفاً لإختلاف ترجمة مفاهيم ومصطلحات هذه النظرية من ترجمة لأخرى إذ إنّ الأمر سيخلق جسوراً من العناء أثناء التواصل مع نظرية التلقي، يكفي أن نرجع إلى ثبت المصطلحات في آخر كل كتاب مترجم ليظهر لنا ذلك . ونحن في حاجة إلى ترجمة كتب أخرى ذات أهمية في هذا المجال حتى تكون الاستفادة أكبر • 
Conclusion

The theory of receptivity has its pros and cons. Among the positive aspects of the theory, critics and those interested in this theory dealt with philosophical currents through the theory of reception, and this interaction deepened their vision of some Western philosophical trends, so this theory served as an incentive to scrutinize the knowledge of these philosophical trends. This theory is positive in the field of creating an important theoretical framework that returns to criticism and Arab culture in general, with a new critical code based on the reader, as Arab critical thought in its entirety is ancient and modern, as it involved the text and the creator without standing at the recipient or the reader, so the theory of receptionBe organized around a literary or artistic receiving activity; In the end, to create a special theoretical framework that would be a development or addition to the general theory of criticism. If these are some of the aspects that we see positive as a result of the effect of the receptive theory on modern Arab criticism, then where are the negative aspects? If we want to turn to these aspects, we will first find that this theory is not complete or complete in order to be able to provide the magic wand to decode creative texts of all kinds. On the other hand, the study of receptivity cannot claim that it is the only scientific approach to literature and literary communication, and this matter makes the researcher deal with this theory with caution.From this standpoint, receptivity theory carries with it weaknesses as well as strengths. This will take us out of the circle of fascination in the theory of reception and access to serious dialogue based on knowledge of the fat from the fat. The verbatim transmission of this theory may not be 
of general interest; Because it may eliminate some important cultural phenomena in a society, the theory proposed by $(($ Yaws $))$ and the methodology that was achieved for it may be useful, indeed, in studying some literary effects and interpreting the type of poetic products in Arabic literature ... But the matter is not that easy if The researcher wanted to follow literary monuments that are not from the peaks inSomething, that is, little creativity, the receptive theory is only concerned with fine texts; Because it does not satisfy the expectations of its audience, and the texts that do not satisfy the expectations of their audience are not worth studying, so we see that the lack of interest in other types of literary effects - which are not from the peaks - a gap in the aesthetic theory of reception.

As for the terms of receptivity theory, they are not all vague and clear at the same time; Therefore, we must deal with awareness and caution on the terminological side of this theory. It should be noted in this aspect that the translation of terms differs from one translation to another.

As for the translation problem, some translations in this field are satisfied with translating chapters from a book, which makes us ignorant of the status of the translated chapter within the book and the status of the other chapters of the translated book, as we need them to complete the picture of the translated book.

This creates difficulties in adequate communication with the other and with the theory of receptivity, especially despite the importance of translating these texts in and of themselves. It is not clear, as we mentioned above, that the translation of the concepts 
and terminology of this theory varies from one translation to another, as the matter will create bridges of trouble during communication with the theory of receptivity. We need to translate other books of importance in this field in order for the benefit to be greater.

\section{المصادر والمراجع}

$$
\text { القرآن الكريم }
$$

1 إيزر، فولفكانك (1995) فعل القراءة نظرية جمالية التجاوب في الأدب ، ترجمة د. حميد الحمداني ، د. الجلالي الكدية ،

$$
\text { مطبعة النجاح الجديدة ، الدار البيضاء }
$$

2_بلمليح ، إدريس (2000) القراءة التفاعلية ، دراسات لنصوص شعرية حديثة ، ط1 ، دار توبقال للنشر والتوزيع ، الدار

$$
\text { - البيضناء }
$$

$$
\text { 3_بلمليح ، إدريس (1994) من قضايا التلقي والتأويل ، ط1 ، مطبعة النجاح الجديدة ، الدار البيضاء. }
$$

4_الجاحظ ، أبوعثمان عمرو بن بحر (1975) البيان والنبيين ، ط 4 ، ج 1، تحقيق ، عبدالسلام هارون ، مكتبة الخانجي ،

5_صالح ، بشرى موسى (2001) نظرية التلقي أصول وتطبيقات ، ط1 ، المركز الثقافي العربي ، الدار البيضاء ، بيروت ،

$$
\text { لبنان. }
$$

6_عبابنة ، سامي (2004) اتجاهات النقاد العرب في قراءة النص الثعري الحديث ، ط2 عالم الكتب الحديث للنشر والتوزيع •

7_ عبد العظيم، محمد (1992) معاني النص الثعري، طرق الإنتاج وسبل الإستقبال، ندوة صناعة المعنى وتأويل النص،

$$
\text { مجلد 8، منشورات كلية الآداب، تونس. }
$$

8_ عبد الواحد، محمود عباس، (1996) قراءة النص وجمالية التلقي بين المذاهب الغربية الحديثة وتراثنا النقدي، دراسة مقارنة،

$$
\text { ط1، دار الفكر العربي، القاهرة. }
$$



9 _ عوض ، يوسف نور ( 1994) نظرية النقد الأدبي ، ط1، مصر ، القاهرة، مصر، القاهرة ، دار الأمين

10_الغذامي ، عبدالله ( 1999) تأنيث القصيدة والقارئ المختلف ، ط1 ، المركز الثقافي العربي ، الدار البيضاء ، بيروت . 11 فوزي ، عيسى (1997) النص الشعري وآليات القراءة ، د ط ، منشأة المعارف ، الإسكندرية. 12_قديد ، مونسي (2004) نظرية الإستقبال عند النقاد الغربيين ، ملتقى الخطاب النقدي العربي المعاصر ، قضاياه واتجاهاته الفنية المركز الجامعي 13_ الماضي، شكري عزيز (2005) في نظرية الأدب، ط1، بيروت، المؤسسة العربية للنشر . 14__ مبروك، مراد عبد الرحمن (2002) آليات المنهج الثكلي في نقد الرواية العربية المعاصرة، ط1، دار الوفاء للطباعة، الإسكندرية.

15_محمد، عبد الناصر حسن (1999)نظرية التوصيل وقراءة النص الأدبي، د ط، المكتب المصري لتوزيع المطبوعات، القاهرة. 16_ مفتاح، د. محمد (1993) نظرية التلقي إشكالات وتطبيقات، مطبعة النجاح الجديدة، الدار البيضاء، الرباط. 17_مفتاح، د. محمد (1993) التلقي التأويل مقاربة نسقية، ط1، المركز الثقافي العربي. 18_ مونسي، حبيب (2000)القراءة و الحداثة، مقاربة الكائن المككن في القراءة العربية، دط، مطبعة اتحاد الكتاب العرب، دمشق.

19 _ياوس ، هانس روبيرت ، جمالية التلقي من أجل تأويل جديد للنص الأدبي ، ط1، تقديم وترجمة د. رشيد بنحدو الناشر منشورات ضنفاف . 20_سي هولب ، روبرت (1992) نظرية الإستقبال مقدمة نقدية ، ترجمة ، رعد عبد الجليل جواد ، ط1،دار الحوار للنشر والتوزيع، اللاذقية ، وترجمها (1994) عز الدين إسماعيل ،ط1، كتاب النادي الثقافي ، جدة . 
مجلة لارك لدفلسفة واللسداذيات و العلوم الاجتماعية المجلد (2) العدد (41) السدذة (2021) بحوث الدغة العربية

21 _هولب ، روبرت (1992) نظرية التلقي مقدمة نقدية ، ترجمة محمد برادة ، مجلة دراسات سميائية أدبية ، عدد 6 .

Sources and references

The Holy Quran

1_Eser, Wolfkank (1995) The act of reading, aesthetic theory of responsiveness in literature, translated by Dr. Hamid Al-Hamdani, Dr. Al-Jalali Al-Kadiya, An-Najah New Press, Casablanca 2_Belmlih, Idris (2000) Interactive Reading, Studies of Modern Poetic Texts, 1st Edition, Dar Toubkal for Publishing and Distribution, Casablanca.

3 _ Belmlih, Idris (1994) from the issues of receiving and interpretation, 1st ed., An-Najah New Press, Casablanca.

4_Al-Jahez, Abu Uthman Amr Ibn Bahr (1975) Al-Bayan and the Two Prophets, ed. 4, c. 1, ed., By Abdul-Salam Haroun, Al-Khanji Library, Egypt.

5_ Salih, Bushra Moussa (2001) The Theory of Receptivity, Origins and Applications, 1st Edition, Arab Cultural Center, Casablanca, Beirut, Lebanon.

6_ Ababneh, Sami (2004), the trends of Arab critics in reading the modern poetic text, 2nd ed. The Modern World of Books for Publishing and Distribution.

7_ Abd Al-Azim, Muhammad (1992) The Meanings of the Poetic Text, Methods of Production and Ways of Reception, Symposium on Meaning Industry and Text Interpretation, Volume 8, Publications of the Faculty of Arts, Tunis. 
8_ Abd al-Wahid, Mahmoud Abbas, (1996) Reading the text and the beauty of receiving between modern Western doctrines and our critical heritage, a comparative study, 1st Edition, House of Arab Thought, Cairo.

9_ Awad, Youssef Nour (1994) The Theory of Literary Criticism, 1st Edition, Egypt, Cairo, Egypt, Cairo, Dar Al-Amin

10_Al-Ghadhami, Abdullah (1999) The feminization of the poem and the different reader, 1st Edition, Arab Cultural Center, Casablanca, Beirut.

11 Fawzi, Issa (1997) Poetic Text and Reading Mechanisms, DT, Al Ma'arif Institute, Alexandria. 12_ Qadeid, Monsie (2004) The Theory of Reception for Western Critics, A Forum for Contemporary Arab Critical Discourse, Its Issues and Artistic Trends, University Center 13_ Al-Mady, Shukri Aziz (2005) in Literature Theory, 1st Edition, Beirut, Arab Publishing Corporation

14 _Mabrouk, Murad Abdel Rahman (2002) Mechanisms of the Formal Approach in the Criticism of the Contemporary Arabic Novel, 1st Edition, Dar Al-Wafa Printing, Alexandria

15_Muhammad, Abdel Nasser Hassan (1999) The Theory of Connectivity and Reading Literary Text, DT, The Egyptian Bureau for the Distribution of Publications, Cairo.

16_ a key, Dr. Mohamed (1993) The Theory of Receptivity, Problems and Applications, AnNajah New Press, Casablanca, Rabat.

17_ a key, Dr. Muhammad (1993) Al-Talqi, Interpretation, a Systematic Approach, 1st Edition, Arab Cultural Center. 
مجلة لارو لدفلسفة واللسدانيات والعلوم الاجتماعية المجلد (2) العدد (41) السذة (2021) بحوث اللغة الـعربية

18 _Mounsi, Habib (2000) Reading and Modernity, An Approach to the Possible Being in Arabic Reading, Dat, Arab Writers Union Press, Damascus.

19 _Jaeus, Hans Rupert, Aesthetics of Receptivity for a New Interpretation of the Literary Text, 1st Edition, Presented and translated by Dr. Rashid Benhdou, the publisher, Defaf publications.

20_C Holb, Robert (1992) Reception Theory, Critical Introduction, Translation, Raad Abdul Jalil Jawad, 1st Edition, Dar Al Hiwar for Publishing and Distribution, Lattakia, and translated (1994) by Ezz El Din Ismail, 1st Edition, The Cultural Club Book, Jeddah.

21_Hulb, Robert (1992) The Theory of Receptivity, a Critical Introduction, translated by Muhammad Barada, Journal of Literary Semiotic Studies, No. 6. 